\title{
Os DiREITOS DOS ACIONISTAS MINORITÁRIOS DIANTE DA TRANSFERÊNCIA DE AGÊNCIAS DE UMA INSTITUIÇÃO FINANCEIRA PARA OUTRA DO MESMO CONTROLADOR
}

\author{
IVES GANDRA MARTINS ${ }^{\dagger}$
}

\section{INTRODUÇÃO}

No presente estudo tratarei da operação de transferência de agências e equipamentos entre instituições financeiras sob o mesmo controle, levando em consideração os seguintes pontos:

- o cálculo deve ser pelo valor de mercado (e não o contábil);

- no valor do preço deve ser computado o fundo de comércio;

- e, por fim, o direito dos acionistas minoritários de serem indenizados por tal operação.

\section{VAlor de Mercado X VAlor Contábil}

Algumas considerações preliminares fazem-se necessárias.

A primeira observação refere-se ao disposto no artigo $117 \S 1$, letra "a", da Lei das Sociedades por Ações, assim redigido:

Art. 117. O acionista controlador responde pelos danos causados por atos praticados com abuso de poder.

$\S 1$ ํㅡão modalidades de exercício abusivo de poder:

a) orientar a companhia para fim estranho ao objeto social ou lesivo ao interesse nacional, ou levá-la a favorecer outra sociedade, brasileira ou estrangeira, em prejuízo da participação dos acionistas minoritários nos lucros

\footnotetext{
† Professor Emérito das Universidades Mackenzie, UNIP, UNIFIEO, UNIFMU, do CIEE/O ESTADO DE SÃO PAULO, das Escolas de Comando e Estado-Maior do Exército - ECEME, Superior de Guerra - ESG e da Magistratura do Tribunal Regional Federal - 1 ${ }^{\underline{a}}$ Região; Professor Honorário das Universidades Austral (Argentina), San Martin de Porres (Peru) e Vasili Goldis (Romênia); Doutor Honoris Causa das Universidades de Craiova (Romênia) e da PUC-Paraná, e Catedrático da Universidade do Minho (Portugal); Presidente do Conselho Superior de Direito da FECOMERCIO SP; Fundador e Presidente Honorário do Centro de Extensão Universitária CEU/Instituto Internacional de Ciências Sociais - IICS.
} 
ou no acervo da companhia, ou da economia nacional; (...). ${ }^{1}$

Embora o dispositivo comporte análise pormenorizada de seus diversos ângulos e espectro abrangente, o que interessa, para efeitos de reflexão no presente estudo, é aquele concernente ao exercício do abuso do poder acionário, ou seja:

favorecer outra sociedade, brasileira ou estrangeira, em prejuízo da participação dos acionistas minoritários nos lucros ou no acervo da companhia. $^{2}$

Se o valor patrimonial da empresa, nele incluído o fundo de comércio, é superior ao valor contábil -e o é, na esmagadora maioria dos casos por força da intangibilidade desse acervo - configura abuso o fato de acionista majoritário integralizar capital de outra empresa da qual não participam os acionistas minoritários, ou, se participam, de forma que tal

${ }^{1}$ Gustavo Leopoldo Caserta Maryssael de Campos, Marcos da Costa e Mérces da Silva Nunes assim o comentam: "A responsabilidade estabelecida neste artigo tem natureza civil. Mas não afastará eventuais responsabilidades de caráter penal ou administrativo, caso o mesmo ato, ou a forma com que for praticado, seja tipificado como ilícito em lei. Dependerá a responsabilização da prova de que o ato foi praticado com abuso de poder, e de que acarretou dano. Seja patrimonial ou moral o dano, deverá ele ser valorado monetariamente, para ser completamente ressarcido. Conforme assinalou Modesto Carvalhosa, o uso regular do poder de controle não é questionável, mesmo que seu resultado seja a não-prosperidade da companhia, em vista da condução ineficiente ou improdutiva das atividades da empresa. O uso do poder só será considerado abusivo se o controlador não atender ao interesse público e societário, mas, sim, ao seu próprio interesse, resultando dano à companhia ou a pessoas a ela ligadas (...)". CAMPOS, G.L.C.M.; COSTA, M.; NUNES, M.S. In: VIDIGAL, G.C; MARTINS, I.G. (Orgs.). Comentários às Leis das Sociedades por Ações. $2^{\underline{a}}$ ed. Rio de Janeiro: Forense Universitária, 1999, p. 353.

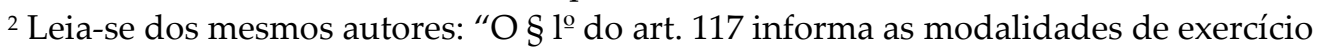
abusivo de poder, sujeitas sanção estabelecida no "caput" do dispositivo. Doutrina relevante tem afirmado que as hipóteses contempladas nas alíneas desse dispositivo têm caráter exemplificativo e não taxativo, calcando-se no seguinte trecho da Exposição de Motivos do próprio projeto: 'exemplificando, o art. 117, modalidades mais frequentes de exercício abusivo do poder controlador, o projeto não exclui outras hipóteses, que da vida e da aplicação da lei se incumbirão de evidenciar'". VIDIGAL, G.C; MARTINS, I.G. (Orgs.). Comentários às Leis das Sociedades por Ações. $2^{\underline{a}}$ ed. Rio de Janeiro: Forense Universitária, 1999, p. 354. 
capital venha se diluído, nos termos do supracitado dispositivo. ${ }^{3}$ Apenas nas aquisições de empresas com ágio pode-se falar em "fundo de comércio adquirido", (Lei 11.638 de 28/12/2007), que não é o caso do presente estudo.

A expressão "levar a favorecer outra sociedade" é suficientemente clara. Não obstante as restrições que os intérpretes sempre fazem ao aforismo exegético de que "in claris cessat interpretatio", neste caso, é difícil fugir à clareza da norma.

Declara o legislador que, se houver "o favorecimento de outra sociedade" que resulte em "prejuízo dos acionistas minoritários", não podem fazer prevalecer sua opinião na decisão, por serem sempre vencidos na divergência eventual - o exercício do poder abusivo é configurado, merecendo as sanções que examinaremos mais adiante. ${ }^{4}$

\footnotetext{
${ }^{3}$ Concluem: "Esclareceu Fran Martins que a lei, ao empregar, de forma generalizada, o verbo orientar, admite que a mesma se faça direta ou indiretamente; será direta quando resultar de voto assemblear; será indireta quando for exercida através de influência ou de pressão sobre o corpo de administradores da companhia. É também considerado abuso de poder o acionista controlador levar a companhia a favorecer outra sociedade, brasileira ou estrangeira, em prejuízo da participação dos acionistas minoritários nos lucros ou no acervo da companhia, ou da economia nacional. Essa regra espelhou a preocupação do legislador com a realidade da economia internacional na década de 70, quando já imperavam as macroempresas transnacionais. No mundo atual, de transações eletrônicas movimentando bilhões de dólares em tempo real, onde uma crise nacional pode causar danos irreparáveis em todo o mundo, essa regra ganha ainda maior importância, ao impedir que os acionistas nacionais e a própria economia brasileira sofram prejuízos enormes, causados por controlador que, nessa hipótese, no mais das vezes, será estrangeiro". VIDIGAL, G.C; MARTINS, I.G. (Orgs.).
}

Comentários às Leis das Sociedades por Ações. $2^{\underline{a}}$ ed. Rio de Janeiro: Forense Universitária, 1999, p. 355.

${ }^{4}$ As demais hipóteses de uso abusivo estão nas letras " $b$ " a " $h$ " do artigo 117, que estão assim redigidas: "§ 1ำ São modalidades de exercício abusivo de poder: a) orientar a companhia para fim estranho ao objeto social ou lesivo ao interesse nacional, ou levá-la a favorecer outra sociedade, brasileira ou estrangeira, em prejuízo da participação dos acionistas minoritários nos lucros ou no acervo da companhia, ou da economia nacional; b) promover a liquidação de companhia próspera, ou a transformação, incorporação, fusão ou cisão da companhia, com o fim de obter, para si ou para outrem, vantagem indevida, em prejuízo dos demais acionistas, dos que trabalham na empresa ou dos investidores em valores mobiliários emitidos pela companhia; c) promover alteração estatutária, emissão de valores mobiliários ou adoção de políticas ou decisões que não tenham por fim o interesse da companhia e visem a causar 


\section{FUNDO DE COMÉRCIO}

Em relação ao denominado "fundo de comércio" repetidas vezes, tenho me debruçado sobre a matéria.

O Ministro José Carlos Moreira Alves em palestra pronunciada no Centro de Extensão Universitária - Escola de Direito do Instituto Internacional de Ciências Sociais sobre o conteúdo desse conceito, assim se referiu (18/11/2011):

Como salienta Rubens Requião ${ }^{5}$, fundo de comércio e estabelecimento comercial são expressões sinônimas, porquanto "na nomenclatura jurídica, usada pelos nossos autores, aplicam-se, comumente, as expressões fundo de comércio, por influência dos escritores franceses (fonds de commerce), e azienda, por inspiração dos juristas italianos, como sinônimas de estabelecimento comercial", razão porque "usaremos, pois, indistintamente os três vocábulos". No mesmo sentido, Fran Martins ${ }^{6}$, que observa que "no Brasil tem sido empregada, para significar o fundo de comércio, a expressão estabelecimento comercial", embora o autor ache mais apropriado usar da expressão fundo de comércio. Por outro lado, são integrantes do fundo de comércio os elementos incorpóreos e corpóreos de que se utilizam os comerciantes em suas atividades, não se podendo dizer, genericamente, qual desses elementos é o preponderante. Daí, e em face do disposto no caput do artigo 133 do CTN que

prejuízo a acionistas minoritários, aos que trabalham na empresa ou aos investidores em valores mobiliários emitidos pela companhia; d) eleger administrador ou fiscal que sabe inapto, moral ou tecnicamente; e) induzir, ou tentar induzir, administrador ou fiscal a praticar ato ilegal, ou, descumprindo seus deveres definidos nesta Lei e no estatuto, promover, contra o interesse da companhia, sua ratificação pela assembleiageral; f) contratar com a companhia, diretamente ou através de outrem, ou de sociedade na qual tenha interesse, em condições de favorecimento ou não equitativas; g) aprovar ou fazer aprovar contas irregulares de administradores, por favorecimento pessoal, ou deixar de apurar denúncia que saiba ou devesse saber procedente, ou que justifique fundada suspeita de irregularidade; h) subscrever ações, para os fins do disposto no art. 170, com a realização em bens estranhos ao objeto social da companhia. (Incluída dada pela Lei no 9.457, de 1997)".

${ }^{5}$ REQUIÃO, Rubens. Curso de Direito Comercial, $1^{\mathbf{0}}$ Volume. $21^{\underline{a}}$ ed. Editora Saraiva: São Paulo, 1993, p. 204.

${ }^{6}$ MARTINS, Fran. Curso de Direito Comercial. 24a ${ }^{\mathrm{a}}$ ed. Editora Forense: Rio de Janeiro, 1999, p. 328. 
versa a sucessão tributária, estar eu de pleno acordo com a resposta do Dr. Ives Gandra da Silva Martins, "verbis": "Trata-se (o fundo de comércio) de rigor, de um conjunto de atributos que determinado negócio adquire, transcendendo de muito a característica de um elemento isolado, como, por exemplo, local, atividade ou mesmo clientela, se isoladamente considerado cada um desses elementos. É o conjunto deles e de outros que constitui aquilo que representa o "fundo de comércio", algo que transcende a própria noção de empresa. O valor do "fundo de comércio" é sempre superior ao da própria empresa, em seus valores escriturais, visto que nele considerado está não só o valor patrimonial da sociedade e do negócio, como todos os elementos que o compõem - como o "goodwill", o "earning power" - além de outros que conformam o seu valor real, de resto, o que é permanentemente considerado para efeitos de alienações empresariais." 7

\section{Em minha opinião:}

Não se pode confundir "acervo" com "fundo de comércio", O fundo de comércio representa, não obstante constituir-se em conceito mais amplo de direito privado e de fronteiras mais elásticas, uma universalidade de bens corpóreos e incorpóreos. Alguns dos juristas que procuraram definir o fundo de comércio, sempre realçaram tais características, no direito pátrio e comparado, como Albert Cohen ("Traité Theorique et pratique des fonds de commerce'), Alfredo Buzaid ('Da ação renovatória', Ed. Saraiva), L. Autuori ('Fundo de Comércio', Repertório Enciclopédico do Direito Brasileiro, Ed. Borsoi, vol. 23, pg. 230), A.B. Cotrim Neto ('Fundo de Comércio', Enciclopédia Saraiva de Direito, vol. 39). ${ }^{8}$

Alfredo Buzaid entende por fundo de comércio o conjunto de todos os bens corpóreos e incorpóreos de uma empresa:

A generalidade dos autores costuma classificar os elementos que compõem o fundo de comércio em duas categorias fundamentais, que reúnem espécies variáveis e de natureza diversa, consoante a importância do ramo e da atividade mercantil: a) direitos ou coisas incorpóreas: 1 - o direito à renovação judicial do contrato de arrendamento; 11 - o nome comercial, compreendendo a firma e a denominação; o título e a insígnia do estabelecimento; a expressão

${ }^{7}$ MARTINS, I.G. Questões controvertidas no Processo Administrativo Fiscal. Rio de Janeiro: Revista dos Tribunais/CEU-Escola de Direito, 2012, p. 16/17.

${ }^{8}$ MARTINS, I.G. (Org.). Responsabilidade Tributária: Pesquisas Tributárias, Novas

Séries 17. Rio de Janeiro: Revista dos Tribunais/CEU-Escola de Direito, 2011, p. 32. 
ou sinal de propaganda; as marcas de indústria e de comércio; as recompensas industriais; as invenções e os privilégios; os modelos de utilidade, os desenhos e os modelos industriais; 111 - os direitos autorais e os de resguardo do nome ou pseudônimo contra os seus usurpadores; IV o aviamento,' a freguesia e sua defesa contra a concorrência desleal; b) coisas corpóreas: 1- os imóveis, a saber, terrenos, construções, edifícios, fábricas, armazéns, depósitos, com tudo neles intencionalmente empregado em sua exploração , industrial, aformoseamento ou comodidade, irretiráveis sem fratura ou dano; 11 - os móveis, i.e., as instalações, o mobiliário, os utensílios, veículos, máquinas, maquinismo, acessórios e pertences, a matéria-prima, os produtos manufaturados ou semimanufaturados, as mercadorias, ou fazendas em geral, os títulos ou efeitos do comércio. ${ }^{9}$

O conceito de fundo de comércio, portanto, leva em consideração não só os bens tangíveis, como aqueles intangíveis, mas ostenta um espectro mais amplo, de valor supra empresarial, em que todos os fatores influenciam sua determinação, inclusive a previsão de lucros futuros (goodwill ou earning power) e a própria possibilidade de sua perfilação, independente da continuação ou não da empresa. ${ }^{10}$ Se o bem que incorpora o fundo tiver reconhecimento atemporal no mercado - como ocorre com algumas empresas que se notabilizaram por suas descobertas e inovações - enquanto estas empresas detiverem tais bens imateriais,

${ }_{9}^{9}$ BUZAID, Alfredo. Da ação renovatória São Paulo: Saraiva, p. 243/4.

${ }^{10}$ O Prof. Wilson Alberto Zappa Hoog lembra que: “O Fundo de Comércio - 'goodwill' tem como uma apreciação contemporânea, o seguinte sentido e alcance: É um bem com uma característica dominante de intangível, podendo existir uma ou mais partes corpóreas, e este ativo-bem não se confunde com ágio, pois pode ser objeto unitário de direitos e de negócios jurídicos, translativos ou constitutivos. Existe somente nas células sociais, que possuem o 'elemento de empresa', independente de ser uma pessoa jurídica, pois o empresário, assim como a sociedade empresária, também tem fundo de comércio - 'goodwill'. Este bem praticamente intangível, o aviamento, está caracterizado como um bem de propriedade desta célula social, e é dotado de valor econômico, podendo este valor ser nulo ou positivo, mas não, negativo; traz benefícios presentes e futuro". HOOG, W.A.Z. Fundo de comércio - "goodwill" - Conceito contemporâneo. Disponível em:

$<$ https://www.google.com.br/\#q=fundo+de+comercio++ "goodwill"+conceito+contemporaneo+Wilson+Alberto> Acesso em: 24 de janeiro de 2016. 
mesmo com paralisação temporária do empreendimento, não perde, o fundo de comércio, densidade própria no mercado. ${ }^{11}$

O fundo de comércio é, portanto, um valor intangível, pertencente a todos os detentores de ações de uma empresa, majoritários ou não, o qual integra o valor global. Por sua difícil quantificação contábil - não pelo mercado -, raramente aparece na contabilidade, mas conforma o valor real da empresa.

Um outro aspecto é de se realçar, preliminarmente, qual seja, o reconhecimento pelos Tribunais Superiores de que o fundo de comércio tem valor a ser dimensionado, devendo, todavia, a sua quantificação ser equiparada ao do ressarcimento, nas dissoluções de sociedade ou retirada de sócios. Embora a jurisprudência tenha se orientado para as dissoluções ou retiradas de acionistas, o mesmo princípio pode ser adotado para outras formas de transformação societária.

No RESP 906123, sob a relatoria do Ministro Paulo de Tarso, decidiu o STJ:

RECURSO ESPECIAL. APURAÇÃO DE HAVERES. DISSÍDIO NÃO CONFIGURADO. COTEJO INEXISTENTE. AUSÊNCIA DE SIMILITUDE FÁTICA ENTRE OS ARESTOS CONFRONTADOS. APURAÇÃO DE HAVERES. INCLUSÃO DO FUNDO DE COMÉRCIO. POSSIBILIDADE. RECURSO A QUE SE NEGA SEGUIMENTO. 1. Não demonstrada a divergência pretoriana conforme preconizado nos arts. 541, parágrafo único,

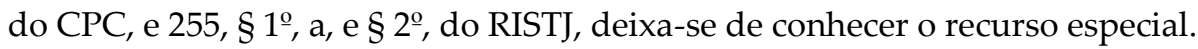
2. A jurisprudência desta Corte Superior firmou-se no sentido de que o critério da apuração de haveres, no caso de sócio que se retira da sociedade, será semelhante ao da dissolução total, ou seja, incluindo-se na avaliação de seus

${ }^{11}$ Paulo Coviello Filho lembra que: “O E. Tribunal de Justiça do Estado de Minas Gerais utiliza definição proveniente do Dicionário Aurélio, nos mesmos moldes das definições aqui relacionadas, conforme abaixo: 'O conceito de fundo de comércio encontrado no Dicionário Aurélio é o seguinte, in verbis: Conjunto de bens e direitos, tangíveis ou não, que constituem o patrimônio do comerciante (instalações, mercadorias, nome e ponto do estabelecimento, freguesia, etc. ') . Aviamento, ainda segundo o Dicionário Aurélio, é o elemento essencial do estabelecimento comercial: o conjunto de aparelhamento, freguesia, crédito e reputação." COVIELLO FILHO, P. A dificuldade e subjetividade na conceituação do fundo de comercio. Disponível em: $<$ http://www.fiscosoft.com.br/a/6gd9/a-dificuldade-e-subjetividade-na-conceituacaode-fundo-de-comercio-paulo-coviello-filho $>$. Acesso em: 24 de janeiro de 2016. 
haveres o fundo de comércio, sob pena enriquecimento dos demais sócios em prejuízo do sócio falecido. 3. Recurso a que se nega seguimento (grifos nossos). ${ }^{12}$

Leia-se idêntica postura no RESP de relatoria do Ministro Cesar Asfor Rocha:

COMERCIAL E PROCESSUAL CIVIL. DISSOLUÇÃO PARCIAL DE SOCIEDADE. APURAÇÃO DE HAVERES. INCLUSÃO DO FUNDO DE COMÉRCIO. JUROS DE MORA. TERMO INICIAL. HONORÁRIOS ADVOCATÍCIOS. ART. 20, § $4^{\circ}$ DO CPC. O fundo de comércio integra o montante dos haveres do sócio retirante. Precedentes. "Dentre os efeitos decorrentes da citação na ação de dissolução parcial da sociedade, ora cogitada, de conteúdo declaratório, não se pode incluir o de acarretar à sociedade ré, ora recorrente, o ônus de já ter de suportar a incidência de juros moratórios desde a citação recebida, pois que estes só poderão fluir a partir do título executivo a ser eventualmente constituído pela sentença que fixar o valor do crédito que possa vir a ser reconhecido à sócia/recorrida"(REsp n. 108.933-SC, por mim relatado, DJ de 30/11/1998). Recurso especial parcialmente conhecido e, nessa extensão, provido (grifos nossos). ${ }^{13}$

No RESP 453476/GO, de relatoria do Ministro Antonio de Pádua Ribeiro, lê-se:

PROCESSUAL CIVIL. AÇÃO RESCISÓRIA. PRAZO. CONTAGEM. TRÂNSITO EM JULGADO. SENTENÇA. UNICIDADE. DISSOLUÇÃO PARCIAL DE SOCIEDADE COMERCIAL. PAGAMENTO DE HAVERES. I A sentença é una, e como tal, não pode ser fracionada para efeito de ação rescisória. Não se pode falar, pois, em trânsito em julgado parcial. Precedente da Corte Especial (ERESP 404.777-DF). II - O prazo para ajuizar ação rescisória é contado a partir do Documento: 13989504 - Despacho / Decisão - Site certificado de trânsito em julgado da decisão no último recurso interposto. III - Para que a ação rescisória seja acolhida por violação a dispositivo de lei (CPC, art. 485, V) é preciso que a norma legal tida como ofendida tenha sofrido violação em sua literalidade. $I V$ - Na dissolução de sociedade comercial, a apuração de haveres no caso de sócio retirante deve ser feita como se de dissolução total se tratasse, evitando locupletamento indevido dos sócios remanescentes. V-Declarando

12 STJ, REsp 908173, Min. Rel. Paulo de Tarso Sanseverino, Publicado em: 22/02/2011.

${ }_{13}$ STJ, REsp 564711/RS, Min. Rel. Cesar Asfor Rocha, Quarta Turma, Publicado em: 20/03/2006. 
o perito judicial que mencionou a marca HSM como componente de fundo de comércio, não há como se fazer ilação para afirmar que, não registrada no INPI a referida marca, direito a ela não teria o sócio retirante. VI - Recurso especial conhecido e provido para cassar o acórdão proferido na ação rescisória (grifos nossos). ${ }^{14}$

Nos três casos, reconhece-se que o fundo de comércio é integrante do valor patrimonial da empresa, mesmo que não quantificado na contabilidade - de resto, raramente há esta contabilização, normalmente apenas feita em aquisições - para que não haja uma perda de substância real do valor patrimonial dos sócios minoritários, nas dissoluções, incorporações, fusões ou cisões, muitas vezes de interesse exclusivo dos controladores, quando não, para afetarem a influência dos sócios minoritários, se em número capaz de pressionar decisões do controlador. ${ }^{15}$

Em outras palavras, o Fundo de Comércio traduz a capacidade da sociedade progredir, o seu valor imaterial, elemento que compõe o próprio valor da empresa, devendo ser quantificado a favor de controladores e minoritários.

Há necessidade aqui de uma rápida explicação.

Algumas decisões judiciais reconhecem que a detenção do controle de uma empresa oferta ao acionista controlador um plus valorativo, por seu poder maior de negociar e comandar.

Este plus superior, em alguns casos, não é de se confundir com o fundo de comércio. Este decorre do valor da empresa, beneficiando controladores e minoritários, pois não é um valor atribuível a cada acionista em particular, mas à empresa como um todo. ${ }^{16}$

14 STJ, REsp 453476/GO, Min. Rel. Antônio de Pádua Ribeira, Terceira Turma, Publicado em: 12/12/2005.

${ }^{15}$ Em acórdão da relatoria do Ministro Castro Meira leia-se: “10. No atual cenário da economia nacional e internacional, altamente dependente da saúde financeira do setor empresarial, a eticidade nas relações interna corporis das companhias é bem jurídico igualmente digno de tutela, por meio do estímulo à segurança e à transparência das operações financeiras.

Por tais motivos, urge aplicar-se o princípio da confiança, a fim de resguardar a boa-fé dos sócios minoritários, bem como de toda a comunidade, diante de eventuais situações jurídicas geradas por um comportamento desleal dos administradores e sócios-controladores das pessoas jurídicas" STJ, REsp 1.130.103/RJ, Min. Rel. Castro Meira, Segunda Turma, Publicado em: 30/08/2010.

${ }^{16}$ Roberta Nioac Prado, ao analisar a OPA (Oferta Preferencial de Ações) lembra que: "Concluindo: é importante que percebamos a crescente importância que se atribui à OPA a posteriori como boa prática de Governança Corporativa. E que a Governança Corporativa, em si, nada mais é do que a constatação, e a posterior proteção, legal ou 
Trata-se de um valor que diz respeito a toda empresa, valor intangível, que, como atrás expliquei, é composto de todos os bens materiais e imateriais que conformam a imagem da entidade no meio em que atua. Independentemente deste valor pode, eventualmente, haver um valor adicional para o conjunto de ações do controlador, que diz respeito ao poder pessoal de dispor de suas ações - tese polêmica -, mas que não se confunde com o fundo de comércio da empresa.

Tal valor, todavia, vale somente para negociações com terceiros. Jamais pode ser considerado nas incorporações, fusões, em face de, nestas alterações, não usar, o acionista controlador, do seu poder pessoal de decisão patrimonial "pro domo sua". Prevalece, para tais hipóteses, exclusivamente o poder real das empresas, com seu fundo de comércio, objetivando uma integração societária, na qual todos os acionistas, minoritários e majoritários, estão representados. ${ }^{17}$

Em relação ao fundo de comércio, é ele intocável como um valor pertinente à empresa, nestas hipóteses, não se confundindo com o valor negocial que eventualmente possua o controlador, de vender as suas próprias ações a terceiros. ${ }^{18}$

estatutária, dos interesses econômicos dos acionistas minoritários, investidores do Mercado de Capitais. Assim sendo, a discussão meramente jurídica sobre a questão perde sua relevância, pois a adoção ou não da oferta pública obrigatória (tag along) para todos os acionistas da companhia quando da alienação de controle, passa a ser vista sob outro viés: uma exigência do mercado para investir nas empresas, com o próprio mercado buscando soluções práticas para as suas necessidades (grifos nossos)". PRADO, R.N. Fundamentos Jurídicos e Econômicos da OPA a Posteriori (Tag Along) e a Questão sob a Ótica de Empresas que Praticam Boas Práticas de Governança Corporativa. Revista Direito GV, Vol. 2, 1, 2006, p. 167/190.

${ }^{17}$ Leia-se no acórdão do EDcl-REsp 1.214.497/RJ, Min. Rel. Raul Araújo, Quarta. Turma, Publicado em: 09/02/2015: "4. Havendo dano direto ao acionista, prevê a Lei a ação individual (LSA, art. 159, $\S 7^{\circ}$ ) e, quando o dano é indireto, possibilita aos acionistas minoritários ingressarem com a ação "ut singuli" (LSA, art. 159, § $4^{\mathrm{o}}$ )". ${ }_{18}$ Embora a Lei 11.638 de 28/12/07, art. 1ํㅡㄹ fale em valores intangíveis para contabilização, tem merecido crítica sobre a extensão, lembrando-se que esta quantificação é mais fácil por força dos valores da negociação. Leia-se de Jeferson Roberto Nonato o seguinte: “Expressamente a lei ordenou a inclusão do "Fundo de Comércio Adquirido" no grupo de contas que irá abrigar os ativos intangíveis direitos adquiridos passíveis de serem identificados, mensurados, reconhecidos, alienados ou ajustados contabilmente pelo impairment test. Entretanto, foi silente quanto à hipótese de ocorrência fática do fenômeno jurígeno. De pronto, não se sabe se o legislador estaria se manifestando no sentido de que toda a diferença, a maior, paga 
Neste ponto, portanto, parece-me claro que são dissociáveis os dois conceitos: o de fundo de comércio da empresa e o do direito individual do acionista controlador de ceder suas ações a terceiros. Possuem valores diversos, o primeiro, quantificável erga omnes, mediante perícias e laudos; o segundo, quantificável de acordo com o direito de cada acionista de alienar suas ações, podendo o aspecto negocial superar os valores intrínsecos da empresa como um todo, até no campo de mera especulação de mercado. O mesmo pode acontecer na hipótese de alienação global da empresa.

Tal distinção é necessária para que não se confunda com o caso em que o acionista controlador beneficiou outra de suas empresas - não negociando com terceiros -, em detrimento dos acionistas minoritários, que viram a empresa ser despatrimonializada por valores escriturais diversos de seus valores reais, se computando seu fundo de comércio. ${ }^{19}$

pelo adquirente ao vendedor, em relação aos ativos líquidos transferidos a valor de mercado (justo valor), seria considerada 'fundo de comércio adquirido', ou, se a expressão, posta na Lei, se refere à ocorrência de o 'fundo de comércio' ser um item individuado, reconhecido e mensurado no ato da combinação do negócio. A dúvida é pertinente porque a Lei poderia mencionar apenas 'Fundo de Comércio' como instituto legal comercial. Mas não é o caso porque a referência legal se faz em razão do fundo de comércio surgido nas transações de aquisição de negócios. Como estamos frente a um arcabouço normativo contábil, pensamos que é nesta disciplina que devamos buscar a resposta e, não outra disciplina comercial. Assim no tema é relevante que se observa as disposições de órgãos com poderes normativos, como é o caso do Comitê de Pronunciamentos Contábeis - CPC - brasileiro". NONATO, J.R. Fundo de comércio adquirido na combinação de negócios (goodwill), 2009. Disponível em: $<\underline{\text { http://www.fiscosoft.com.br/a/4o5l/fundo-de-comercio-adquirido-na- }}$ combinacao-de-negocios-"goodwill"-jeferson-roberto-nonato $>$. Acesso em: 24 de janeiro de 2016. Repito que, nesta hipótese, que não se confunde com a deste estudo, que não cuida de alienação de ações, mas transferência de patrimônio de uma empresa para outra do mesmo controlador em detrimento dos acionistas minoritários. ${ }^{19}$ Leia-se no acórdão já citado de relatoria do Min. Castro Meira o seguinte: “11. A Lei das Sociedades por Ações também é informada por essa principiologia, como se extrai da Exposição de Motivos n.․ 196, de 24 de junho de 1976, segundo a qual a responsabilidade social que passou a ser exigida dos acionistas-controladores e dos administradores das pessoas jurídicas impõe-lhes comportamento idôneo e probo, conforme as diretrizes lançadas nos artigos 116, 117, 153 e 154, da Lei n.o 6.404/76" (grifos nossos). STJ, REsp 1.130.103/RJ, Min. Rel. Castro Meira, Segunda Turma, Publicado em: 30/08/2010. Há, pois, um valor intrínseco à empresa que constitui seu valor de 
Ora, o fato de ter, o acionista controlador, utilizado seu poder de comando para despatrimonializar a empresa, o deixar de considerar o fundo de comércio, transferindo bens para outra empresa de seu controle - o que não se confunde com o direito de alienar suas ações a terceiros - em detrimento dos acionistas minoritários, leva-me a uma outra consideração, que diz respeito ao enriquecimento sem justa causa, a custa de terceiros, que pode chegar, inclusive, a transformar-se em enriquecimento ilícito de variada natureza, com implicações civis, penais etc.

\section{DO ENRIQUECIMENTO ILÍCITO}

A ninguém é dado beneficiar-se, por exercício abusivo de poder, de valores que deveriam pertencer a todos, enriquecendo-se, em decorrência, ilicitamente, do seu ato..$^{20}$

Em decisão do Tribunal de Justiça de São Paulo, de relatoria de Cesar Ciampolini, restou reconhecido que:

Ação de declaração de nulidade de venda de ativo social de companhia, feita a preço irrisório. Abuso de poder do sócio majoritário. Ato de liberalidade parcial, consistente na venda a preço muitas vezes menor do que o do ativo alienado. Doutrina de MODESTO CARVALHOSA. A venda de ativo social, em companhia, há de se fazer por valor real, pena de configurar, ao menos na parte faltante para se chegar ao verdadeiro valor, ato de liberalidade, vedado pelo $\S 2 \mathrm{o}$, a, do art. 154 da Lei das Anônimas. Prova emprestada, que merece, no caso concreto, cabal prestígio. Doutrina de AMARAL SANTOS. Imprestabilidade da perícia feita nos autos, posto que por valores contábeis, notoriamente irreais. Jurisprudência a respeito da imprestabilidade, nestes casos, de dados

mercado e um outro, nas companhias abertas, principalmente, em que, inclusive, o aspecto especulativo momentâneo pode ser diverso.

20 "Nemo auditur propriam turpitudinem allegans é um direito civil máxima que pode ser traduzido para o Inglês como "ninguém pode ser ouvido para invocar a sua própria torpeza" ou "ninguém deve ser ouvido, que invoca a sua própria culpa". A máxima operado com outro, em pari causa turpitudinis cessat repetitio (onde ambos os partidos são culpados, ninguém pode se recuperar), para impedir um órgão jurisdicional de intervir em uma disputa envolvendo uma transação ilegal". Disponível em:

$<$ https://en.wikipedia.org/wiki/Nemo auditur propriam turpitudinem allegans $>$. Acesso em: 24 de janeiro de 2016. 
contábeis. O minoritário, na demanda contra ato de abuso de controle do majoritário, não precisa adentrar em prova de índole subjetiva; é suficiente que traga aos autos ato que importe em objetiva demonstração do dano. Doutrina (FÁBIO COMPARATO e outros) e jurisprudência a respeito (Ministra NANCY ANDRIGHI). Ato nulo, de ratificação impossível; ou, quando não, ausência de ratificação em assembleia, que para tanto não foi convocada. "Ratificar não é uma correção que se faz de forma implícita" (Desembargador ÊNIO ZULIANI). Responsabilidade solidária do sócio controlador, e de todos os partícipes do ato fraudulento, pelas perdas e danos sofridas pelo minoritário. Apuração do "quantum debeatur" em liquidação de sentença. Apelação a que se dá provimento (grifos nossos). ${ }^{21}$

À evidência, a transferência, para outra empresa de controle dos acionistas controladores, de agências, por valores contabilizados sem a inclusão do valor do fundo de comércio (clientes, patrimônio, movimentação, ponto, mercado etc.), representou um benefício para a empresa receptora dos bens, com enriquecimento de seus detentores em detrimento de acionistas minoritários, correspondendo a situação análoga à do acórdão citado, em que o patrimônio foi avaliado por valor inferior ao seu valor real.

No mesmo sentido, leia-se ementa do acórdão do STJ, de relatoria do Ministro Castro Meira, já citado em nota de rodapé anterior:

RECURSO ESPECIAL. REVISÃO. FATOS. SÚMULA 07/STJ. PROPORCIONALIDADE. ARTIGO 11, § 1으. DA LEI N. 6.385/76. TRINTA POR CENTO DO VALOR DA OPERAÇÃO IRREGULAR. POSSIBILIDADE. PROPORCIONALIDADE. MULTA. INTERDIÇÃO TEMPORÁRIA DO EXERCÍCIO DA ATIVIDADE DE ADMINISTRADOR. CUMULATIVIDADE. CABIMENTO. PROIBIÇÃO DA PROTEÇÃO DEFICIENTE AOS BENS JURÍDICOS. INTERPRETAÇÃO SISTEMÁTICA E TELEOLÓGICA. CABIMENTO. PODER DE POLÍCIA. DISCRICIONARIEDADE. 1. Os recorrentes realizaram operação de mútuo com "holdings" familiares, na época em que ocupavam concomitantemente as funções de administradores e sócios controladores da pessoa jurídica, contudo, na contabilidade da empresa, fizeram registrar esta operação como se fosse "saldo a receber de clientes", ao invés de a lançarem como mútuo, razão pela qual a Comissão de Valores Mobiliários aplicou-lhes as sanções de multa e de inabilitação para o exercício do cargo de administrador, pelo prazo de dez anos, com base nos artigos 117

${ }^{21}$ TJ-SP, Apelação 9167807-48.2007.8.26.0000, Des. Rel. Cesar Ciampolini, Décima Câmara de Direito Privado, Data de Julgamento: 05/02/2013. 
e 153, da Lei n. ${ }^{\circ}$ 6.404/1976, e 11 da Lei n.. 6.385/76. [...] 9. Constatou-se falta de transparência na realização da operação financeira em destaque, com impacto direto sobre o patrimônio da empresa e sobre o direito à informação dos acionistas minoritários, quando a companhia encontrava-se sob orientação decisiva dos recorrentes, acionistas controladores e administradores à data dos fatos. [...] (grifos nossos)..$^{22}$

Seguindo a mesma linha, o acórdão do TJ-MG:

LIQUIDAÇÃO DE SENTENÇA - DISSOLUÇÃO PARCIAL DE SOCIEDADE COMERCIAL - SENTENÇA SUCINTA - QUESTÕES ANALISADAS APURAÇÃO DE HAVERES QUE DEVEM REPRESENTAR O VALOR REAL E EFETIVO DOS BENS MATERIAIS E IMATERIAIS. Não é nula a sentença que analisa todas as questões de fato e de direito apresentadas pelas partes na fase de liquidação, em estrita observância do requisito formal assim previsto no CPC, 458, II. A apuração judicial de haveres, efetivada através de operação técnico-contábil, é o procedimento correto para a verificação da situação patrimonial do sócio que se afasta, com objetivo de obter-se o quantum relativo ao seu capital. O pagamento, à data da liquidação, deve refletir o real patrimônio social da empresa, isto é, o conjunto de créditos e débitos, de bens materiais e imateriais - não apenas aquele utilizado com o objetivo de avaliação dos bens em balanço. ${ }^{23}$

Assim, segundo o entendimento esposado por Tribunais diversos e de níveis diversos de competência, o enriquecimento ilícito do acionista majoritário à custa do minoritário não é permitido. Leia-se:

APELAÇÃO CÍVEL. CONSIGNAÇÃO EM PAGAMENTO. DISSOLUÇÃO DE SOCIEDADE COM APURAÇÃO DE HAVERES. FUNDO DE COMÉRCIO. MULTA NOS EMBAROS DE DECLARAÇÃO PELO NÍTIDO CARÁTER PROTELATÓRIO. PENALIDADE DEVIDA. RECURSO CONHECIDO E DESPROVIDO. A apuração dos haveres objetiva descobrir o quantum devido pela sociedade ao sócio retirante, pelo valor das quotas sociais deste, considerado o valor efetivo, real e atualizado do patrimônio da sociedade (bens materiais e imateriais). O fundo de comércio integra a apuração dos haveres, a fim de evitar enriquecimento ilícito da sociedade e dos sócios

${ }^{22}$ STJ, REsp 1.130.103/RJ, Min. Rel. Castro Meira, Segunda Turma, Publicado em: 30/08/2010.

${ }^{23}$ TJ-MG, MG 2.0000.00.355115-7/000(1), Des. Rel.Wander Marotta, Data de Publicação: $09 / 02 / 2002$. 
remanescentes. Justifica-se a multa do art. 538, p. único, do CPC, no nítido caráter protelatório dos embargos de declaração (grifos nossos). ${ }^{24}$

É de se acentuar, neste último acórdão, a necessidade de apuração de haveres, com a integração do fundo de comércio na apuração de valor. ${ }^{25}$

Ora, a transferência de agências para empresa do acionista controlador comporta a determinação do fundo de comércio correspondente, exteriorizando, a ausência desse elemento, um prejuízo para os acionistas minoritários. Com efeito, foram eles despojados, na empresa de que participavam, do valor real correspondente às agências transferidas, em situação análoga àquela examinada e decidida pelos tribunais, nos acórdãos retrocitados.

É enriquecimento sem justa causa o que se faz à custa de outrem, no exercício de um poder que este não possui, empobrecendo-o, por retirarlhe benefício a que teria direito, em face de sua posição de domínio. Tal enriquecimento, a que não teria direito, se não se apropriasse de tais bens em razão de seu poder decisório, transforma-se, à falta de justa causa, em enriquecimento ilícito, pois só ocorreu pelo exercício abusivo da posição de domínio. ${ }^{26}$

${ }_{24}$ TJ-SC, AC 316.485, Des. Rel. Domingos Paludo, Terceira Câmara de Direito Comercial, Data de Julgamento: 14/10/2010.

${ }^{25}$ Leia-se em ementa de acórdão que: "APURAÇÃO DE HAVERES - Ação movida por sócio excluído da sociedade - Metodologia "goodwill" adotada justificadamente na perícia, dentre as várias possibilidades existentes, que deve-se ter como correta, até porque as impugnações oferecidas não vêm respaldadas em parecer técnico - O "goodwill", que é um dos ativos intangíveis, não pode ser desconsiderado na apuração dos haveres, sob pena de enriquecimento indevido Apelação desprovida" TJ-SP, AC 9.094.411, Des. Rel. Alcides Leopoldo e Silva Júnior, Primeira Câmara de Direito Privado, Data de Julgamento: 27/05/2014.

${ }^{26}$ Mesmo que a empresa tenha prejuízos, o fundo de comércio deve ser avaliado. Leiase: “DIREITO SOCIETÁRIO. DISSOLUÇÃO PARCIAL DE SOCIEDADE. APURAÇÃO DEHAVERES. INCLUSÃO DO FUNDO DE COMÉRCIO. 1. De acordo com a jurisprudência consolidada do Superior Tribunal de Justiça, o fundo de comércio (hoje denominado pelo Código Civil de estabelecimento empresarial - art. 1.142) deve ser levado em conta na aferição dos valores eventualmente devidos a sócio excluído da sociedade. 2. O fato de a sociedade ter apresentado resultados negativos nos anos anteriores à exclusão do sócio não significa que ela não tenha fundo de comércio. 3. Recurso especial conhecido e provido. (...) ACÓRDÃO A Turma, por unanimidade, conheceu do recurso especial e deu-lhe provimento, nos termos do voto do Sr. Ministro Relator. Os Srs. Ministros Março Búzio, Luis Felipe Salomão, Raul Araújo e 


\section{Do Direito dos Acionistas Minoritários}

Agências com valores reais acima do valor contábil - onde o fundo de comércio computado foi zero - foram transferidas para empresas de controle exclusivo dos sócios majoritários, restando nítido o seu enriquecimento indevido contra o empobrecimento dos acionistas minoritários, que viram o valor de seu patrimônio, constante da empresa na qual participam, em parte amputado, pois recebendo, na referida transferência de agências, contrapartida menor que seu valor real. Houve, à evidência, ação abusiva e enriquecimento indevido do acionista controlador das duas empresas. ${ }^{27}$

Tal conclusão leva-me, aqui, a uma consideração, qual seja, à obrigação do controlador de ambas as sociedades (a prejudicada e a beneficiada) de indenizar os danos patrimoniais e eventualmente morais sofridos pelos minoritários.

Um primeiro ponto a se ter em conta, embora a matéria ainda seja objeto de polêmica no campo doutrinário e jurisprudencial, é o cabimento ou não de um valor adicional pelo controle acionário, nas OPA (oferta pública de ações).

No caso em questão, não há, todavia, alienação de bens, mas transferência de parte do patrimônio, sem perda de controle de um bem pertencente a todos acionistas e com fundo de comércio próprio (cada

Maria Isabel Galati votaram com o Sr. Ministro Relator. Brasília-DF, 11 de outubro de 2011 (Data do Julgamento)". STJ, REsp 907.014, Min. Rel. Antonio Carlos Ferreira, Quarta Turma, Data de Julgamento: 11/10/2011.

${ }^{27}$ Através de Planiol e Ripert, (Traite pratique de drois civis franças, cit., t. 6, n. 574, p. 781), reafirma-se que a abuso não se confina, apenas, "aos atos realizados por espírito de malevolência". PLANIOL, M.; RIPERT, G. Traité Pratique de Droit Civil Français, Tome VI. Paris: Librarie Générale de Droit et de Jurisprudence, 1930. Bem explica o abuso do direito a teoria que o considera em vista das "exigente Di socialite", frente aos meios a que se recorre para exaurir a potencialidade do direito. Cf. TRABUCAI, A. Istituzioni di Diritto Civile. 45a ed. Padova: CEDAM, 2011, p. 55. Para DEMOGUE, R. Traité des Obligations en Général, Tome 3. Paris: Librarie Arthur Rousseau, 1931, p. 440, “uma obrigação de agir aparecerá cada vez mais para cada um à medida que a ideia individualista de liberdade seja substituída pela de uma posição social atribuída a cada qual com uma certa ideia de independência", de modo que a medida da liberdade de um, ao exercer seu direito, seja deferida pelo direito do outro de não ser prejudicado, pois neminem laedere. 
agência detém um fundo de comércio diverso, pelo número de clientes, movimentação, posição no mercado, capacidade de gerar lucro próprio), para outra entidade sob o mesmo controle, sem ter sido considerado este valor (valor do fundo de comercio), cuja contabilização era zero.

É tal prejuízo, a ser quantificado, que merece ressarcimento, para que os acionistas controladores beneficiados com a transferência, remunerem os acionistas por ela prejudicados, com a indenização patrimonial correspondente. ${ }^{28}$

Essa indenização deve ser quantificada com base em laudos elaborados por peritos insuspeitos, independentes e de renome, para embasar futuras ações.

Por ser o fundo de comércio, um bem intangível, muitos autores consideram haver dificuldade em determinar seu valor, razão pela qual os peritos a serem contratados devem ostentar três condições: insuspeição, quer dizer, não devem estar vinculados a qualquer dos grupos; autonomia e independência, possuindo um passado profissional que possa comprovar tal forma de agir; notabilidade (qualidade técnica

${ }^{28}$ Como não houve ressarcimento do prejuízo à sociedade a que pertencem os acionistas minoritários, a indenização deve ser direta aos acionistas minoritários, como "a contrário sensu" há de se interpretar a decisão anexa: "PROCESSUAL CIVIL E SOCIETÁRIO. AÇÃO PROPOSTA POR ACIONISTAS MINORITÁRIOS EM FACE DE ADMINISTRADORES QUE SUPOSTAMENTE SUBCONTABILIZAM RECEITAS. AJUIZAMENTO DE AÇÃO INDIVIDUAL PARA RESSARCIMENTO DE DANOS CAUSADOS À SOCIEDADE EMPRESÁRIA. ILEGITIMIDADE ATIVA

RECONHECIDA. - Os danos diretamente causados à sociedade, em regra, trazem reflexos indiretos a todos os seus acionistas. Com o ressarcimento dos prejuízos à companhia, é de se esperar que as perdas dos acionistas sejam revertidas. Por isso, se os danos narrados na inicial não foram diretamente causados aos acionistas minoritários, não detém eles legitimidade ativa para a propositura de ação individual com base no art. 159, § $7^{\circ}$, da Lei das Sociedades por Ações. Recurso Especial não conhecido. (...) ACÓRDÃO Vistos, relatados e discutidos estes autos, acordam os Ministros da TERCEIRATURMA do Superior Tribunal de Justiça, na conformidade dos votos e das notas taquigráficas constantes dos autos, por unanimidade, não conhecer do recurso especial, nos termos do voto da Sra. Ministra Relatora. Os Srs. Ministros Sidnei Beneti e Ari Pargendler votaram com a Sra. Ministra Relatora. Pelo $1^{\circ}$ recorrido: Dr. Marcelo Henriques Ribeiro de Oliveira Brasília (DF), 04 de março de 2008 (data do julgamento)." STJ, REsp 1.014.496, Min. Rel. Nancy Andrighi, Terceira Turma, Data de Julgamento: 04/03/2008. No caso, fora a empresa ressarcida do prejuízo, que não é a hipótese da consulente. 
de seu trabalho deve ser indiscutível) e notoriedade (de conhecimento geral). ${ }^{29}$

A partir daí, é possível determinar o fundo de comércio, com todos os aspectos que conformam o patrimônio real, não apenas contábil, mas também o intangível.

Não sem razão, com a edição do Código Civil e as discussões que se colocaram sobre o fundo de comércio de que resultou o artigo 1142 daquele diploma assim redigido:

Art. 1.142. Considera-se estabelecimento todo complexo de bens organizado, para exercício da empresa, por empresário, ou por sociedade empresária.

Seus ilustres autores introduziram a expressão "todo complexo", objetivando não excluir qualquer elemento material ou imaterial na conformação do perfil de estabelecimento. ${ }^{30}$

${ }^{29}$ Leia-se o seguinte trecho de acórdão: “RECURSO ESPECIAL. DIREITO PROCESSUAL CIVIL E DIREITO SOCIETÁRIO. ART. 117, § 1., DA LEI N. 6.404/76 (LEI DAS SOCIEDADES). MODALIDADES DE ABUSO DE PODER DE ACIONISTA CONTROLADOR. FORMA EXEMPLIFICATIVA. CARACTERIZAÇÃO DO ABUSO DE PODER. PROVA DO DANO. PRECEDENTE. MONTANTE DO DANO CAUSADO PELO ABUSO DE PODER DO ACIONISTA CONTROLADOR. FIXAÇÃO

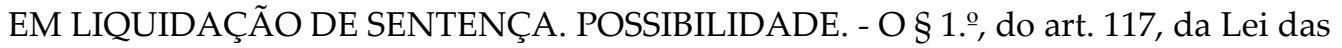
Sociedades Anônimas enumera as modalidades de exercício abusivo de poder pelo acionista controlador de forma apenas exemplificativa. Doutrina. - A Lei das Sociedades Anônimas adotou padrões amplos no que tange aos atos caracterizadores de exercício abusivo de poder pelos acionistas controladores, porquanto esse critério normativo permite ao juiz e às autoridades administrativas, como a Comissão de Valores Mobiliários (CVM), incluir outros atos lesivos efetivamente praticados pelos controladores. - Para a caracterização do abuso de poder de que trata o art. 117 da Lei das Sociedades por ações, ainda que desnecessária a prova da intenção subjetiva do acionista controlador em prejudicar a companhia ou os minoritários, é indispensável a prova do dano. Precedente (grifos nossos)". STJ, REsp 798.264/SP, Min. Rel. Carlos Alberto Menezes Direito, Terceira Turma, Publicado em: 16/04/2007.

${ }^{30}$ Ricardo Fiúza e Newton de Lucca assim se referem ao dispositivo: "Elogiável a distinção a que procedeu o Código entre empresa e estabelecimento, mostrando que este - corriqueiramente designado por fundo de comércio - nada mais é do que a projeção patrimonial daquela, constituindo um conjunto de bens, corpóreos e incorpóreos, unidos pela vontade e determinação de seu titular que é o empresário. Não se deve, com efeito, confundir o conceito de fundo de comércio com o de aviamento ou o de clientela. Era muito comum, em nosso meio, aludir-se à antiga Lei 
O conceito de estabelecimento encontrado no direito internacional, como a unidade produtora de bens empresariais - podendo ser composta de um único estabelecimento ou de um conjunto de estabelecimentos, como filiais, agências etc. (todos os tratados internacionais contra dupla tributação assinados pelo Brasil ancoram-se no conceito de estabelecimento da empresa multinacional) demonstra que a agência estabelecimento isolado - tem um desenvolvimento próprio, com seu respectivo fundo de comércio. ${ }^{31}$

Assim é que uma agência bancária em bairro de grande concentração de empresas tem maior poder de ganho que uma instalada em bairro operário, possuindo, pois, seu fundo de comércio próprio.

Ora, na quantificação da indenização material a ser definida, a apuração do fundo de comércio da agência, embora complexa, é

de Luvas como sendo urna lei protetora do fundo de comércio. Tal impropriedade era flagrante porque o que essa lei protegia, na verdade, era o aviamento - resultado de um conjunto de variados fatores pessoais, materiais e imateriais, que conferem a dado estabelecimento in concreto a aptidão de produzir lucros". FIÚZA, R; LUCCA, N. Código Civil Comentado. $7^{a}$ ed. São Paulo: Saraiva, 2010, p. 1051. Na famosa explicação do Prof. Oscar Barreto Filho, um dos atributos do estabelecimento. Também aviamento e clientela não se confundem, inexistindo entre eles uma relação de causa e efeito, conforme aparentemente se afigura. Consoante os ensinamentos do citado Prof. Oscar, inspirado numa lei da física, o que há é uma interação desses dois atributos do estabelecimento. São suas palavras: "Os comercialistas atrás citados estavam certos quando diziam, ora que a clientela é o resultado do aviamento, ora que o aviamento resulta da clientela. O que ocorre, em verdade, é a interação mútua dos dois atributos do estabelecimento. Enquanto o melhor aviamento contribui para o aumento da clientela, também esta influi para conservar ou acrescer o aviamento. Qualquer um deles pode ser considerado a 'ação' e o outro a 'reação'. Causa e efeito não estão implícitos na relação entre os dois conceitos mas sim uma interação mútua e simultânea". BARRETO FILHO, O. Teoria do Estabelecimento Comercial: Fundo de Comércio ou Fazenda Mercantil. São Paulo: Max Limonad, 1969, p. 180. E conclui o citado professor: "Esta concepção, que nos foi sugerida pelas leis da física, explica suficientemente a nosso ver, a natureza do fenômeno aviamento-clientela". BARRETO FILHO, O. Código Civil Comentado. 9ae ed. São Paulo: Saraiva, 2013, p. 1068.

${ }^{31} \mathrm{O}$ artigo 1143 do Código Civil está assim redigido: “Art. 1.143. Pode o estabelecimento ser objeto unitário de direitos e de negócios jurídicos, translativos ou constitutivos, que sejam compatíveis com a sua natureza." 
manifestamente possível, podendo ser determinado, inclusive, o earning power, com critérios já adotados em outros países. ${ }^{32}$

No que diz respeito à Lei das S/A e à história da CVM, que protegem o direito do acionista, vale realçar o artigo $159, \S 7^{\circ}$, desse diploma, assim redigido:

Art. 159. Compete à companhia, mediante prévia deliberação da assembleiageral, a ação de responsabilidade civil contra o administrador, pelos prejuízos causados ao seu patrimônio. [...] § $7^{0}$ A ação prevista neste artigo não exclui a que couber ao acionista ou terceiro diretamente prejudicado por ato de administrador.

Como já mencionamos, o dever de lealdade no controle da empresa e seu exercício não abusivo é fundamental. Se o administrador, todavia, é apenas um agente do acionista controlador, o prejuízo que causou a

${ }^{2}$ Marcelo Fortes Barbosa Filho comenta o artigo 1142 do Código Civil dizendo: “Considerada a empresa, tal qual afirmado no art. 966, uma estrutura complexa e capaz de ser examinada de quatro ângulos ou perfis diferenciados, o estabelecimento empresarial corresponde a seu perfil patrimonial. A produção ou a circulação de mercadorias ou serviços precisa, para ser desenvolvida, do agrupamento de bens corpóreos e incorpóreos dotados de destinação econômica específica, organizados e dispostos racionalmente para a execução da atividade profissional própria à empresa. Forma-se, assim, uma universalidade, ou seja, um bem coletivo que conforma um todo único, mas heterogêneo. A vontade de um empresário, manifestada por meio de decisões individuais e interligadas, envolve o conjunto composto por uma quantidade variável de bens singulares, de identidade e qualidade totalmente díspares, vinculando-o a uma mesma finalidade econômica e dotando-o, por isso, de unidade. Surge, então, como universalidade de fato, dado seu enquadramento na definição contida no caput do art. 90, o estabelecimento empresarial. Seja qual for o empreendimento realizado, haverá sempre um estabelecimento, pois o empresário necessitará se aproveitar de algum suporte material, somando-se, por exemplo, materiais de escritório, bens de capital, marcas, patentes ou veículos, tudo integrado pelos mesmos desígnios volitivos. O estabelecimento pode ser simples, concentrandose todos os bens num único local geográfico, mas, também, assume a forma complexa e pode apresentar ramificações, estendendo-se a locais diferentes, sob a forma de sucursais ou filiais, de acordo com a magnitude e o conteúdo da atividade escolhida. A variabilidade é bastante grande, contrastando, inclusive, o estabelecimento urbano, voltado para o comércio ou para a indústria, com o estabelecimento rural, voltado para a agricultura ou a pecuária". BARBOSA FILHO, M.F. Código Civil Comentado. $6^{\mathrm{a}} \mathrm{ed}$. Barueri: Manole, 2012, p. 1107. 
mando do acionista controlador é de responsabilidade de ambos. Cabe a ação referida contra os dois. É que o dever de lealdade, exigido do administrador, é decorrência do princípio da confiança que deve ter o acionista minoritário - que não dirige a companhia - naquele que exerce o direito de controle e conforma a administração. Deve, pois, o acionista majoritário responder ao lado do administrador pelo prejuízo causado ao acionista minoritário. Pode, inclusive, desembocar, a ação de reparação de danos civis, em indenização por danos morais, se prejuízo desta natureza decorrer para o acionista minoritário - como diminuição de sua credibilidade financeira, por exemplo, junto a entidades bancárias, por diminuição do valor de suas ações, em decorrência da despatrimonialização da empresa da qual participava. ${ }^{33}$

\section{CONCLUSÃO}

Ante todo o exposto, concluo que:

I. O valor do fundo de comércio deve ser computado, para cada estabelecimento transferido -no caso das agências, cada uma com um fundo de comércio próprio. Caso tais valores não sejam computados, gerarão um enriquecimento, a meu ver, ilícito, por força do domínio do ato, para o acionista controlador, e um prejuízo real, para o acionista minoritário, privado do valor pleno de seus bens e desprovido da capacidade de decidir sobre a transferência, à falta de poder de ação deliberativa.

II. Se o fundo de comércio não for computado, caberá aos acionistas minoritários receber uma indenização correspondente devendo tal indenização ser bem quantificada "a priori" nos seus valores imateriais, por laudo de especialista, insuspeito, autônomo, independente, de notório e notável saber, capaz de, por critérios nacionais e internacionais de definição do fundo de comércio, goodwill, earning power, definir os valores correspondentes à real potencialidade do fundo de comércio detectado. A indenização não deve ser paga à empresa, mas, exclusivamente, ao acionista minoritário. É que a transferência para outra empresa do mesmo controlador apenas a ele próprio beneficiou e tornou-se um ato irreversível. Em outras palavras, o prejuízo dos acionistas minoritários

${ }^{33}$ No caso concreto, repito, não há que se confundir com o já citado acórdão do REsp. 1.014.496. É que, no presente caso, a transferência por valor contábil beneficiou exclusivamente o acionista controlador de ambas as companhias em prejuízo direto aos minoritários participantes da sociedade, enquanto que no da relatoria da Ministra Nancy Andrighi faz ela menção a prejuízos à companhia. 
decorreu exclusivamente de exercício abusivo do poder do acionista controlador, através de operação de transferência de agências tornada irreversível. Teve o acionista controlador um benefício em sua outra empresa à custa do prejuízo causado aos acionistas minoritários naquela em que exerceu abusivamente o direito de mando.

\section{REFERÊNCIAS}

BARBOSA FILHO, M.F. Código Civil Comentado. $6^{\mathrm{a}}$ ed. Barueri: Manole, 2012.

BARRETO FILHO, O. Código Civil Comentado. 9ª ed. São Paulo: Saraiva, 2013.

BARRETO FILHO, O. Teoria do Estabelecimento Comercial: Fundo de Comércio ou Fazenda Mercantil. São Paulo: Max Limonad, 1969.

BUZAID, Alfredo. Da ação renovatória São Paulo: Saraiva.

COVIELLO FILHO, P. A dificuldade e subjetividade na conceituação do fundo de comercio. Disponível em:

$<$ http://www.fiscosoft.com.br/a/6gd9/a-dificuldade-e-subjetividade-naconceituacao-de-fundo-de-comercio-paulo-coviello-filho $>$. Acesso em: 24 de janeiro de 2016.

DEMOGUE, R. Traité des Obligations en Général, Tome 3. Paris:

Librarie Arthur Rousseau, 1931.

FIÚZA, R; LUCCA, N. Código Civil Comentado. $7^{\mathrm{a}}$ ed. São Paulo: Saraiva, 2010.

HOOG, W.A.Z. Fundo de comércio - "goodwill” - Conceito contemporâneo. Disponível em:

$<$ https://www.google.com.br/\#q=fundo+de+comercio+- 
+" goodwill"+conceito+contemporaneo+Wilson+Alberto> Acesso em: 24 de janeiro de 2016.

MARTINS, Fran. Curso de Direito Comercial. 24ª . ed. Editora Forense: Rio de Janeiro, 1999.

MARTINS, I.G. (Org.). Responsabilidade Tributária: Pesquisas

Tributárias, Novas Séries 17. Rio de Janeiro: Revista dos

Tribunais/CEU-Escola de Direito, 2011.

MARTINS, I.G. Questões controvertidas no Processo Administrativo

Fiscal. Rio de Janeiro: Revista dos Tribunais/CEU-Escola de Direito, 2012

PLANIOL, M.; RIPERT, G. Traité Pratique de Droit Civil Français, Tome VI. Paris: Librarie Générale de Droit et de Jurisprudence, 1930.

PRADO, R.N. Fundamentos Jurídicos e Econômicos da OPA a Posteriori (Tag Along) e a Questão sob a Ótica de Empresas que Praticam Boas Práticas de Governança Corporativa. Revista Direito GV, Vol. 2, 1, 2006.

REQUIÃO, Rubens. Curso de Direito Comercial, $1^{0}$ Volume. $21^{\underline{a}}$ ed. Editora Saraiva: São Paulo, 1993.

TRABUCAI, A. Istituzioni di Diritto Civile. 45aㅡ ed. Padova: CEDAM, 2011.

VIDIGAL, G.C; MARTINS, I.G. (Orgs.). Comentários às Leis das

Sociedades por Ações. 2ª ed. Rio de Janeiro: Forense Universitária, 1999.

Os Direitos dos Acionistas Minoritários Diante da Transferência de Agências de uma Instituição Financeira para outra do mesmo Controlador The Rights of Minority Shareholders Before the Transference of Agencies to another Financial Institution of the same Controller 